\title{
A case of tacrolimus-induced supraventricular arrhythmia after kidney transplantation
}

Um caso de arritmia supraventricular induzida

por tacrolimus, após o transplante renal

Bo-Ra Kim', Ho-Sik Shin", Yeon-Soon Jung'"', Hark Rim"

Department of Internal Medicine, Kosin University College of Medicine, Busan, Korea

'MD. Fellowship, Department of Internal Medicine, Kosin University College of Medicine, Busan, Korea.

"MD. Assistant Professor, Kosin University College of Medicine, Gospel Hospital, Busan, Korea.

"'MD, PhD. Associate Professor, Department of Internal Medicine, Kosin University College of Medicine, Busan, Korea.

"MD, PhD. Professor, Department of Internal Medicine, Kosin University College of Medicine, Busan, Korea.

KEY WORDS:

Tacrolimus.

Arrhythmias, cardiac.

Kidney transplantation.

Tachycardia, supraventricular.

Atrial premature complexes.

\section{PALAVRAS-CHAVE:}

Tacrolimo.

Arritimias cardíacas.

Transplante de rim.

Taquicardia supraventricular.

Complexos atriais prematuros.

\section{ABSTRACT}

CONTEXT: Tacrolimus is a potent immunosuppressive drug often administered to transplant recipient patients and exhibits a variety of adverse cardiovascular effects.

CASE REPORT: We report a case of a 53-year-old Asian female who developed various arrhythmic phenomena including atrial premature complexes and supraventricular tachycardia after administration of tacrolimus.

CONCLUSION: Tacrolimus-associated arrhythmia after kidney transplantation may be life-threatening, and so patients undergoing this procedure should be carefully monitored.

\section{RESUMO}

CONTEXTO: Tacrolimus (tacrolimo) é uma potente droga imunossupressora frequentemente administrada a pacientes receptores de transplante e exibe uma variedade de efeitos cardiovasculares adversos. RELATO DE CASO: Relatamos um caso de uma mulher asiática de 53 anos de idade que desenvolveu vários fenômenos de arritmias, incluindo complexos atriais prematuros e taquicardia supraventricular após a administração de tacrolimus.

CONCLUSÃO: Tacrolimus associado a arritmia após transplante de rim pode ser fatal, por isso, pacientes submetidos a esse procedimento devem ser cuidadosamente monitorados. 


\section{INTRODUCTION}

Tacrolimus, a potent immunosuppressive drug often administered to transplant recipients, exhibits a variety of adverse cardiovascular effects. The common symptoms are chest pain and hypertension, and abnormal electrocardiographic findings have also been reported. ${ }^{1,2}$ Supraventricular tachycardia (SVT) has never before been reported as an adverse effect of tacrolimus in adults. Here, we present a case of tacrolimus-induced supraventricular arrhythmia after renal transplantation.

\section{CASE REPORT}

The patient was a 53-year-old woman with immunoglobulin A nephropathy resulting in end-stage renal failure. After ten years of hemodialysis, she underwent cadaveric kidney transplantation. The patient had no past history and no family history of cardiac dysrhythmia, syncope or sudden death. An electrocardiogram one day prior to surgery showed normal sinus rhythm, and an echocardiogram showed mild cardiomegaly with normal systolic function.

After the operation, methylprednisolone, mycophenolate mofetil and tacrolimus were administered. The tacrolimus dose was gradually increased from $3 \mathrm{mg}$ twice a day, and sporadic atrial premature beats were detected on the second postoperative day (POD 2). The tacrolimus blood concentration had increased to $10.6 \mathrm{ng} / \mathrm{ml}$. The tacrolimus dose was decreased, and the blood concentration then decreased to close to $8 \mathrm{ng} / \mathrm{ml}$.
On POD 3, the incidence increased significantly, accompanied by appearance of SVT and sporadic ventricular premature beats (Figure 1). The tacrolimus blood concentration was measured and had again increased to $17.9 \mathrm{ng} / \mathrm{ml}$. The SVT was controlled with amiodarone and beta blocker. The reduced drug dose was continued, and the blood concentration was maintained close to $8 \mathrm{ng} / \mathrm{ml}$; arrhythmia did not recur at this level. In both episodes, electrolytes (sodium, potassium and calcium) were within normal ranges (Table 1). QT and QTc were 400/500 ms on POD 2 and 374/467 ms on POD 3. In our case, the QTc data and tacrolimus concentration were not correlated.

\section{DISCUSSION}

Tacrolimus is one of the most frequently used immunosuppressive agents, and arrhythmia is a little-recognized adverse effect. Tacrolimus is a macrolide compound that is considered to prolong QT intervals and result in torsades de pointes. ${ }^{3}$ A systematic survey of indexed articles using the MeSH (Medical Subject Headings) terms "tacrolimus" and "arrhythmia" in databases revealed that only five articles have been published on this topic to this date. All of these papers were found in the Medline, Embase, Lilacs and Cochrane Library databases (Table 2). ${ }^{1-5}$

Johnson first reported prolonged QT intervals and torsades de pointes after tacrolimus administration in a ten-year old patient who underwent liver transplantation. ${ }^{1}$ A second report involved a 35-year-old woman with a long history of renal

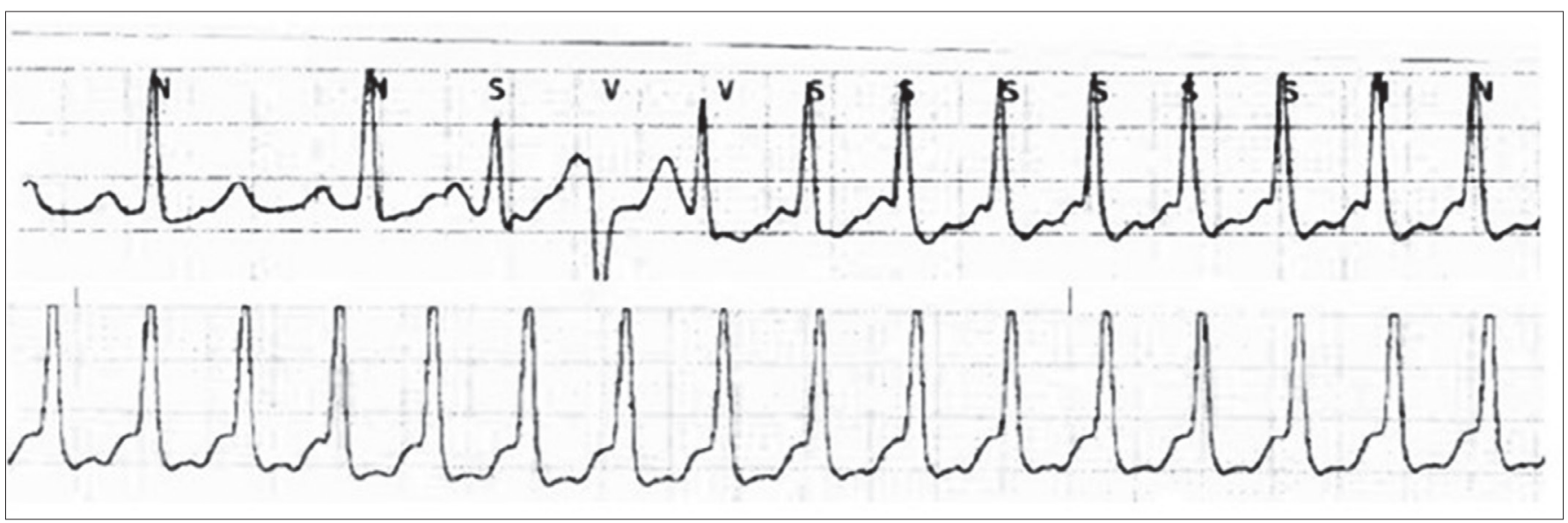

Figure 1. Electrocardiogram (EKG) on the patient: ventricular premature beats were detected (upper trace). Soon after the ventricular ectopic beat, supraventricular tachycardia developed (lower trace).

Table 1. Serum chemistry, QT interval and tacrolimus concentration

\begin{tabular}{|c|c|c|c|c|c|}
\hline Day & QT & QTC & Potassium (mEq/l) & Calcium (mg/dl) & Tacrolimus concentration ( $\mathrm{ng} / \mathrm{ml}$ ) \\
\hline Pre-op & 442 & 493 & 4.5 & 9.0 & \\
\hline POD 1 & 404 & 526 & 4.4 & 8.1 & \\
\hline POD 2 & 376 & 487 & 4.7 & 8.4 & 10.6 \\
\hline POD 3 & 400 & 500 & 4.5 & 8.6 & 8.8 \\
\hline POD 4 & 396 & 469 & 4.4 & 9.1 & 17.6 \\
\hline
\end{tabular}

Pre-op $=$ preoperative; $\mathrm{POD}=$ postoperative day. 
Table 2. Results from our reviews of medical databases using descriptors for the main clinical findings observed in our patient: October 26, 2012

\begin{tabular}{|c|c|c|}
\hline Data base & Search strategy & Results \\
\hline PubMed & "Tacrolimus" AND "arrhythmia" & $\begin{array}{c}4 \text { case reports }^{1-4} \\
1 \text { review of the } \\
\text { literature }^{5}\end{array}$ \\
\hline Embase & "Tacrolimus" AND "arrhythmia" & $\begin{array}{c}4 \text { case reports }^{1-4} \\
1 \text { review of the } \\
\text { literature }^{5}\end{array}$ \\
\hline Lilacs & "Tacrolimus" AND “arrhythmia” & $\begin{array}{c}4 \text { case reports }^{1-4} \\
1 \text { review of the } \\
\text { literature }^{5}\end{array}$ \\
\hline $\begin{array}{l}\text { Cochrane } \\
\text { Library }\end{array}$ & "Tacrolimus" AND "arrhythmia" & $\begin{array}{c}4 \text { case reports }^{1-4} \\
1 \text { review of the } \\
\text { literature }^{5}\end{array}$ \\
\hline
\end{tabular}

failure due to systemic lupus erythematosus. ${ }^{2}$ In both cases, tacrolimus was infused intravenously to more rapidly increase the drug concentration. It was thus suggested that use of intravenous tacrolimus might be temporally related to these tachyarrhythmias. The third reported case involved a one-year-old girl who underwent liver transplantation in whom, despite a comparatively low concentration of tacrolimus, various arrhythmic phenomena including atrial premature beats, SVT and ventricular tachycardia (VT) were observed. Tacrolimus was orally administered in that case; however, the patient had hepatic dysfunction, which appeared to affect the metabolism of tacrolimus and prolong the half-life of the drug. ${ }^{4}$ Recently, ventricular arrhythmia occurring in kidney transplant recipients was reported, with the prevalence of associated factors. In the multiple logistic regression analysis, male gender and coronary artery calcification score were independently associated with the presence of ventricular arrhythmia. ${ }^{5}$

In our case, the patient was an adult female, and the coronary artery calcification score was not evaluated. However, the electrocardiogram showed normal sinus rhythm, and the echocardiogram showed mild cardiomegaly with normal systolic function. In addition, tacrolimus was administered orally and there was no indication of hepatic dysfunction or other causes that would reduce the half-life of the drug. The maximum tacrolimus blood concentration was $17.9 \mathrm{ng} / \mathrm{ml}$, i.e. within the therapeutic range $(5-20 \mathrm{ng} / \mathrm{ml})$. Tacrolimus is a commonly used immunosuppressant, and patients in whom it is administered should be carefully monitored for cardiac dysrhythmia.

\section{CONCLUSION}

After kidney transplantation, a 53-year-old woman developed tacrolimus-induced supraventricular arrhythmia. Tacrolimusassociated arrhythmia may be life-threatening and patients who take the drug, intravenously or even orally, should be carefully monitored.

\section{REFERENCES}

1. Johnson MC, So S, Marsh JW, Murphy AM. QT prolongation and Torsades de Pointes after administration of FK506. Transplantation. 1992;53(4):929-30.

2. Hodak SP, Moubarak JB, Rodriguez I, et al. QT prolongation and near fatal cardiac arrhythmia after intravenous tacrolimus administration: a case report. Transplantation. 1998;66(4):535-7.

3. Minematsu $T$, Ohtani $H$, Sato $H$, Iga $T$. Pharmacokinetic/ pharmacodynamic analysis of tacrolimus-induced QT prolongation in guinea pigs. Biol Pharm Bull. 1999;22(12):1341-6.

4. Nishimura M, Kim K, Uchiyama A, et al. Tacrolimus-induced lifethreatening arrhythmia in a pediatric liver-transplant patient. Intensive Care Med. 2002;28(11):1683-4.

5. Marcassi AP, Yasbek DC, Pestana JO, et al. Ventricular arrhythmia in incident kidney transplant recipients: prevalence and associated factors. Transpl Int. 2011;24(1):67-72.

\section{Sources of funding: None}

Conflict of interest: None

Date of first submission: February 15, 2012

Last received: October 26, 2012

Accepted: December 27, 2012

Address for correspondence:

Ho-Sik Shin

Department of Internal Medicine

Kosin University College of Medicine,

262 Gamcheon-ro, Seo-gu, Busan 602-702

Korea

Tel. +82-51-990-6108

Fax. +82-51-248-5686

E-mail: danieljoseph@hanmail.net 